\title{
Cavernous Nerve Electrical Stimulation
}

National Cancer Institute

\section{Source}

National Cancer Institute. Cavernous Nerve Electrical Stimulation. NCI Thesaurus. Code C150370.

Stimulation of the cavernous nerve with an electrical current for the purpose of treating neurogenic cases of erectile dysfunction. 